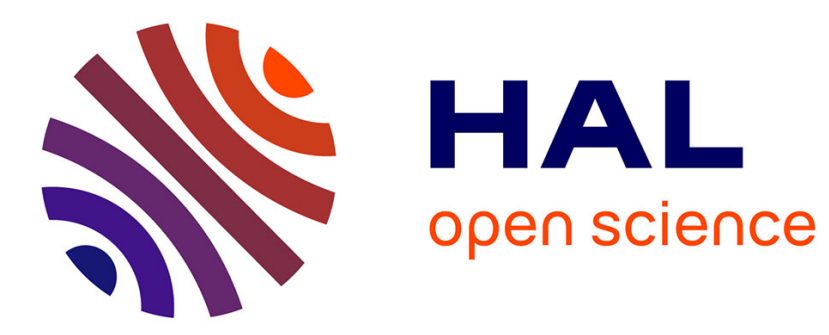

\title{
Tolerance Reflectively Analyzed
}

Lester Embree

\section{To cite this version:}

Lester Embree. Tolerance Reflectively Analyzed. Analysis. Claves de Pensamiento Contemporáneo, 2018, 21 (5), pp.1 - 12. 10.5281/zenodo.2559579 . hal-02163074

\section{HAL Id: hal-02163074 https://hal.science/hal-02163074}

Submitted on 24 Jun 2019

HAL is a multi-disciplinary open access archive for the deposit and dissemination of scientific research documents, whether they are published or not. The documents may come from teaching and research institutions in France or abroad, or from public or private research centers.
L'archive ouverte pluridisciplinaire HAL, est destinée au dépôt et à la diffusion de documents scientifiques de niveau recherche, publiés ou non, émanant des établissements d'enseignement et de recherche français ou étrangers, des laboratoires publics ou privés. 


\title{
Tolerance Reflectively Analyzed
}

\author{
LESTER EMBREE
}

\begin{abstract}
A B STRACT: Tolerance is analyzed first by distinguishing the cultural attitude termed "tolerating" from the specific attitudes of others that are tolerated. Next the roles of believing; of three types of valuing in two combinations; and of the neutral willing characteristic of this practical cultural attitude of tolerating are clarified. Finally, some remarks are offered about how the tolerating of attitudes in others might sometimes be justified for new as well as old cases.
\end{abstract}

KEYWORDS: Reflective Analysis; Phenomenology; Attitude; Value.

ARTICLE HISTORY: Received: 2-January-2017 | Accepted: 30-January-2017

\section{INTRODUCTION}

1. The expression "reflective analysis" is my attempt to capture concisely what phenomenology is as an approach. In a recently published book of the same name, I attempt an extensive introductory reflective analysis of reflective analysis itself. The present essay is another exercise in reflective analysis or phenomenology.

2. Some colleagues have heard me complain in recent years about research that is considered by its authors to be phenomenological when it is merely scholarship on texts by grand figures and not investigation of any things themselves. Such research is merely scholarship not only because it is about texts, but also because it relies on methods no different than those used to interpret the work of Kant, Descartes, or Aristotle. Its method is not that of phenomenological investigation, which is, of course, reflective analysis. Philology is not phenomenology. 
3. And, in my opinion, what phenomenology most needs today are modest reflective analyses that can show by example what phenomenology can do. Here I am undertaking one of these on the cultural attitude called tolerance.

4. One can attempt merely to describe tolerance phenomenologically, but to be philosophical, one's account also needs to address how the thing in question is justified. Accordingly, the present essay has two main parts: the first is on what tolerance is, and the second explores how it can be justified.

\section{WHAT IS TOLERANCE?}

5. Most of us have some sense of what tolerance is, so the task here is chiefly one of clarifying something already encountered more or less obscurely. The effort of clarification involves reflective observation and the feigning of examples. Sometimes such an effort can begin with a dictionary definition, and this can be done here. According to The American Heritage College Dictionary ( $3^{\text {rd }}$ ed., Boston \& New York: Houghton Mifflin Company, 1993), tolerance is "The capacity for or practice of recognizing and respecting the beliefs or practices of others." Most would probably agree that this is a fairly good definition, while also acknowledging that it could be more elaborate. Thus it can be added that the values and valuings encountered in others can also be tolerated in tolerance. Beyond this, what might "the capacity for or practice of," "recognizing," and also "respecting" in this definition signify?

6. Before looking into these matters, it may be stated methodologically that the approach of reflective analysis has a twofold theme consisting of encounterings (noeses) and, correlatively, things-as-encountered (noemata) and that investigation can then be guided by recognizing two parallel or correlative sets of components: on the one hand, there are the abstractly discernable components of-in the broad significations-experiencing, believing, valuing, and willing within any concrete encountering and, on the other hand, there are the abstractly discernable manners of givenness, belief characteristics, values, and functional characters or, better, uses in any concrete things-as-encountered. If one is clear about what experiencing, 
believing, valuing, and willing in the broad significations are, then one is better able to find what a phenomenologist has reflectively observed and described and thus what one is invited to search for in attempting to verify and refine an account.

7. The words "capacity" and "practice" in the dictionary definition can be clarified (a) by recognizing what are best called attitudes, which are repeatable patterns of encountering; (b) by recognizing that the thetic or positional attitudes are specified according to whether it is believing, valuing, or willing that predominates in them; (c) by answering the question of what sort of attitude tolerance is; and (d) by recognizing that attitudes can be actualized or inactual.

8. An analogy may help clarify the last point mentioned: the experiential attitude of recollection is actualized when one is actually remembering something previously encountered, but it is inactual when one is instead perceiving or expecting something. And for positional attitudes, when one is in, for example, a doxic attitude, and thus predominantly engaged in believing in something, attitudes of the volitional-practical sort, in which one would be predominantly engaged in willing something, as well as those of the affectivevaluational sort, in which one would predominantly be valuing something, are inactual. With this clarification of the contrast between actualized and inactual attitudes, the words in the dictionary definition, "the capacity for or practice of...," can be replaced by "the inactual or actualized attitude of...."

9. While tolerance is a possible attitude that is actualized or inactual, it appears not to be a necessity. In other words, one can feign a person who has no attitude of tolerance. But many people in many societies today not only have this attitude toward some things, but also deliberately teach it to others. Then tolerance is an acquired or habitual attitude; it is part of some traditions, and can thus be said to be cultural. If this is so, and if it is justified, then it is right to foster it.

10. If tolerance is an attitude, if an attitude is composed of encounterings, and if encounterings are intentional (or, better, intentive)-i.e., encounterings of things in the broad signification whereby anything can be a 
thing - then attitudes are attitudes toward things, and it can be asked what a case of tolerance is an attitude toward. By the amended dictionary definition used as the point of departure here, the things encountered in tolerance are the beliefs, values, and practices of others. These can be more precisely described as believings and things-as-believed-in by others; valuings and things-as-valued by others; and willings and things-as-willed by others. Concisely put, "the attitudes of others" are what are tolerated in tolerance. What the tolerated attitude is an attitude toward then becomes central because it specifies the tolerance. For example, a vegetarian might tolerate non-vegetarians.

11. "Tolerance" might be used in an extended signification for cases in which inanimate things are focal, such as the sand in one's shoes chafing one's feet while one walks on the beach, but in the broad signification it is restricted to animate things. What one tolerates may also include a non-human animal, e.g., a dirty dog sleeping in the bed of a sick child and comforting her. What tolerance in a strict signification is directed toward are the beliefs, values, and practices of other humans. The present initial analysis will be chiefly confined to that signification.

12. What might "recognizing and respecting" in the definition signify? These two words refer to different matters. Recognizing can be taken to refer chiefly to belief. The vegetarian, for example, recognizes that the nonvegetarian is willing to eat meat, and in contrast, the non-vegetarian believes that the vegetarian is not willing to eat meat. Attempts to justify such believings can be undertaken on the basis of hearing what the other says as well as what $\mathrm{s} / \mathrm{he}$ is observed to do at meals. We readily understand the attitudes of others in most cases. There may be more to what "recognizing" can signify with respect to tolerance, but it suffices here to take it as referring to believing along with its evidential basis in comprehending the speech from others as well as perceiving the actions of others.

13. The matter apparently referred to with the word "respecting" in the initial dictionary definition also needs clarification. Then the whole situation becomes considerably more complex and interesting because of how valuing and values are involved. As already implied, tolerance is a social as well as 
cultural attitude. Both the tolerating person and the person tolerated have relevant attitudes that include valuings intentive to things that correlatively have values. There are two levels of valuing in tolerance. On the first level, there is a difference between the valuing in the tolerating, and the valuing in the attitude tolerated. If they were the same, it would not be a case of tolerance, but of agreement and sympathy.

14. Whether or not the valuings predominate in the attitude, it can be asked whether the ones of interest within the attitude of tolerating are positive, negative, or neutral. Here neutral valuing can be set aside; if the allegedly tolerant person was entirely apathetic about the thing in question, it would also not be a case of tolerance. This leaves positive and negative valuing. The first-level valuing involved in tolerance is comparative, or more specifically, contrastive. Thus each of the people in our example is prepared to say, "My attitude toward the eating of meat is good and yours is bad." Each of the parties positively values his/her own attitudes toward meat eating at the same time that the vegetarian disvalues the diet of the non-vegetarian and the non-vegetarian disvalues the herbivore's diet.

15. Perhaps not in all cases, but in this sample case of vegetarianism vs. non-vegetarianism, both sides can usually go on to give reasons-the vegetarian referring, perhaps, to health advantages, environmental benefits, and the ethical treatment of non-human animals and the non-vegetarian referring, for example, to traditional diets and the genetically determined instincts in omnivores. There are also counter-arguments. Such arguments, however, are arguments for attitudes toward meat eating and not attempts to justify tolerance itself, something returned to below.

16. But tolerance involves more than the complex first-level contrastive valuing composed of positive self-valuing and negative other-valuing. This can best be seen in relation to the component predominating in the attitude of respect also mentioned in the dictionary definition. Even though the types of valuing involved are essential to it, the attitude of respect is a volitional or practical attitude, one in which willing predominates. This may not be obvious in the many cases where the thing respected - the other's attitudedoes not require conspicuous support, i.e., where one simply lets the attitude 
of the other be, i.e., volitional neutrality, but it can be discerned through reflective analysis.

17. Neutral letting-be is a volitional-practical neutrality such that even though one disagrees with the other's attitude, one does not will against it. Praxically negative attitudes might include arguing against the other attitude, discouraging inclusion of particular food items on restaurant menus, engaging in political actions, or even resorting to terrorism. But if there is such negative action against other attitudes, it is not a case of tolerance but of intolerance. The same must also be said about aggressively promoting one's own attitude against those of others, "aggressively promoting" being more than making one's attitude known politely, teaching it to one's children, and requesting equal representation for meat or for vegetables in menus. Thus, tolerance must be classified as a predominantly volitional-practical attitude. Despite the importance that valuing also has within it, it is always a neutral willing of the attitude of the other that predominates there. The tolerant person refrains from opposing the attitudes that $\mathrm{s} / \mathrm{he}$ disvalues.

18. Moreover, even though tolerance is a practical attitude, yet another valuing can be discerned within it, one that functions at a different level than the first-level contrastive valuing described. Reflective observation discloses that tolerance include altogether three valuings. They are involved in two combinations. First, there is the reflexive valuing by which the self s own attitude is approved of; second, there is the valuing by which the other's attitude is disapproved of; and third, there is a valuing of something else. If there were only self-valuing and other-disvaluing, then willings and actions against the other would indeed be motivated for both parties, but this does not happen. Vegetarians could intolerantly oppose "carnivorous" others and non-vegetarians could intolerantly oppose "herbivorous" others. But when the parties are tolerant they do not do so.

19. From what has already been said, it is clear that tolerance is not an attitude in which the own and other attitudes are valued equally, i.e., neither the vegetarian nor the non-vegetarian would say, "We have different attitudes each of which is as good as the other." Rather, there is the comparative valuing of one's own attitude, whichever it is, over the other's attitude. And still, when 
there is tolerance, there is no willing against others of different attitudes. Why?

20. When the third and higher-level valuing comes into play, it overrides the lower valuing that otherwise would have motivated willing against the other person. This third and overriding valuing is essential for tolerance. Why, for example, does a person of one position not act against somebody of the opposite position on the eating of meat? At one extreme, a vegetarian might not kill a meat eater because the positive valuing of human life overrides the disvaluing of meat eating. At the other extreme, a meat eater might not ridicule a vegetarian because s/he prefers not to disrupt the pleasant meal, the pleasant meal thus being valued higher than striking a blow against vegetarianism. Then again, sand chafing feet within walking shoes can be preferred to the burning sand and the comforting of the sick child can override the disvaluing of the dirty dog in the bed. It is this third and overriding valuing that motivates the neutral willing in the practical respecting found in tolerance.

21. The overriding valuing in tolerance is thus a valuing directed toward something other than the disvalued attitude of the other: something is valued more highly than either the aggressive advancement of one's own attitude or the impeding of the opposite attitude, and this higher-level is the stronger when it comes to motivating action. And the willing or action here is indeed a type of respect, one that is action actively neither in support of nor in opposition to the attitude of the other that is respected in the case of tolerance.

22. The dictionary definition taken as point of departure-namely, "The capacity for or practice of recognizing and respecting the beliefs or practices of others"-has now been clarified with respect to inactual and actualized attitudes; positive, negative, and neutral believing, valuing, and willing; respecting as a predominantly volitional-practical attitudes, involving noninterference with the attitudes of others; and higher-level valuings that can override other valuings. 


\section{THE PROBLEM OF THE JUSTIFICATION OF TOLERANCE}

23. For a person raised in a culture of tolerance, the question, "Why be tolerant?" might seem odd. In philosophy, however, even the most taken-forgranted things need to be questioned. This "why question" can, of course, be construed as a question of causes or influences. Then one is interested in how a person who is tolerant came to have that attitude. Such a question can indeed be relevant for ethnology, psychology, sociology, or another cultural science. Answers to that version of the why question are also crucial for practical disciplines such as politics and pedagogy. For philosophy, however, the "why question" is construed as a question of rationality or justification. ${ }^{1}$ In phenomenology, justification is a matter of the relation between the experiencing playing the role of evidencing (Evidenz), on the one hand, and the believing, valuing, and willing directly or indirectly founded upon and motivated by such experiencing, on other hand.

24. Although one also needs to observe how things-as-encountered have manners of givenness, belief characteristics, values, and uses that can be objectivated if one wishes to formulate arguments, the problem of justification is clearest with respect to the components within the encountering, and thus the attitude.

25. To begin with, there is the epistemological question of the justification of believing in, for example, an attitude toward eating meat. The believing in question might be intentive to the self s own attitude or intentive to another's attitude. Self-observation would be relied on in the former case and, in the latter, there is reflection on others based on observing their public eating behavior as well as comprehending their linguistic expressions. The question of epistemological justification is a question of whether the believings can be directly founded upon and motivated by evidencing of these sorts. As mentioned, it is not difficult in most cases to justify believing that the other is an herbivore or an omnivore.

1 On how valuing can be rational, cf. Dorion Cairns, "Reason and Emotion," Husserl Studies, 17 (2000), passim 
26. That such direct and indirect experiencing can serve as evidencing that justifies believing is plausible for most trained in Western philosophy, which is not to say that an elaborate reflective analysis is not still called for. Furthermore, many people are similarly comfortable with the justification whereby valuing justifies willing or action. If one chooses chocolate ice cream and is asked to justify that choice, it is a prima facie justification to say, "I like the taste of chocolate more than the tastes of other flavors, i.e., I prefer it." The attempts at justifying herbivorous and omnivorous actions might also begin in this way, but then go on to the founding cognitive claims about health and environmental consequences, genetic inheritances, culinary traditions, etc.

27. These claims raise epistemological questions of believings about what conduces to what. In parallel fashion, there are, axiologically speaking, intrinsic values-e.g., for someone who enjoys chocolate, the positive intrinsic value of its taste-and extrinsic values, e.g., the negative extrinsic value of fattening food where obesity has intrinsic negative value.

28. An acute problem for philosophy is the justification of valuing, some saying that "there is no accounting for taste." To be sure, there are many things that are beyond justification. For example, some people prefer to back into parking places in parking lots while lots of others prefer to park their cars facing inward. The many things that are indeed merely matters of taste would entail skepticism if there were not also some things that were not merely subjective in this way. It is justified for all sane and informed adult humans that there is a difference between health and illness, that health is justifiably preferred, and that it is justifiably chosen over illness. With such a significant case of justified valuing and willing, skepticism is refuted. Is tolerance such a thing, or is it merely a matter of taste?

29. Although people raised in a culture of tolerance may speak of being tolerant in general, reflective analysis discloses that tolerance itself only occurs as specified. Exactly what is being tolerated, and for the sake of what higher good, will vary. Thus what can be offered here is not a justification for tolerance in general, but a method of justification that might be employed in particular cases. The thing encountered in tolerance is, as established above, 
the attitude of an other or others, and this will always be a particular attitude, e.g., vegetarianism in vegetarians. Upon reflection, that which is encountered in such an encountering-i.e., the attitude tolerated in the other-can be analyzed with respect to its being experienced, believed, valued, and willed by the self who tolerates it. As tolerated, the attitude tolerated then has its own manner of givenness, belief characteristics, values, and uses for the tolerating person. The other's attitude is indirectly experienced on the basis of perceiving behavior and comprehending linguistic expressions. It can have positive belief characteristics for the tolerant person of it and thereby be said to have positive existence, or one can simply say that it exists.

30. As established, the practical characteristic or use for the tolerant person of the attitude tolerated is neither positive nor negative but neutral. Then one abstains from either supporting or opposing the attitude in question of the other. When this neutral willing does indeed predominate, so that tolerance is a practical attitude, there is an interesting complexity concerning the values involved. On a lower level, for the tolerant person her own attitude has positive value and she can say that it is good, while the attitude tolerated has negative value for her and she can say it is bad. On a higher level, however, there is something (e.g., the preservation of human life or of a pleasant dining atmosphere) that has a higher and positive value for the tolerant person, and one can speak of such more highly valued things and their positive values in arguing for the justification of tolerance. Thus the question of justification must above all address the third, higher-level good and show not only how it is positive, but also how it outranks the lower and bad attitude in the other person. One must also examine the higher end and the intrinsic value and existence of that which is tolerated. Whether actualized or an inactual disposition, tolerance is always encountered as specified, and the work of justification must discern and examine the higher-level value involved in each specific case. 


\section{CLOSING REMARKS}

31. Clearly the above analysis calls for further analysis. For example, is there not a positive willing of the neutral willing characteristic of tolerance? There is space on this occasion for only two additional comments. In the first place, is there is something that is non-relative in the area of tolerance somewhat like how health is non-relatively valuable? Here at least one thing comes to mind for the present writer. This is the form of intolerance called genocide, i.e., the attempt of some societies to destroy other societies, such as the invading Europeans did to the aboriginal peoples in the Americas. ${ }^{2}$ No doubt many tolerated that intolerance in that era, but can that tolerance of intolerance be justified? I think not

32. Secondly, one might distinguish between shallow and deep tolerance. In the former, one has been conditioned to be tolerant of various things, many of them being quite significant, e.g., differences of religion, and one can also have learned strong arguments in support of these serious tolerances. These arguments would be epistemological and praxiological as well as axiological. Still, they are chiefly arguments received in childhood, when one was taught by others to be tolerant. Such a type of tolerance ought not to be disparaged, but it can still be mistaken and naïve. It needs constantly to be examined.

33. In deep tolerance, as it may be called, it is recognized, on the other hand, that whether or not to be tolerant in old as well as new situations, on the other hand, and how tolerance might be justified in each case, , on the other hand, are both critical tasks-indeed, infinite critical tasks.

With rapid social change in the present era one faces situations where previously overlooked differences-e.g., the different cultural attitudes encountered in men and women, the different attitudes toward other ethnic groups, or the different attitudes toward non-human animals-become focal and new types of tolerances may be called for. In such cases, one recognizes that there is an especially pressing need for justifying not only the first-level self-approval and other-disapproval, but also the second-level positive

2 See David E. Stannard, American Holocaust: Columbus and the Conquest of the New World (New York: Oxford University Press, 1992). 
valuing that overrides the other-disapproval and motivates the mode of willing that makes tolerance a practical attitude in which neutral willing predominates. Whether to be tolerant or intolerant is constantly a problem for reflective analysis.

LESTER EMBREE Department of Philosophy Florida Atlantic University 777 Glades Road - SO 283

Boca Raton, FL 33431-0991 embree@fau.edu

\section{References}

Cairns, Dorion (2000). "Reason and Emotion.” Husserl Studies 17.

Stannard, David E. (1992). American Holocaust: Columbus and the Conquest of the New World. New York: Oxford University Press. 